\title{
COVID-19 ile Mücadelede Fizyoterapistlerin Girişimcilik Niyetleri ve Önündeki Engellerin İncelenmesi
}

Assessment of Physiotherapists' Entrepreneurial Intentions and Barriers in Fighting Against COVID-19

\author{
İbrahim YIKILMAZ1 , Seval KUTLUTÜRK²
}

\begin{abstract}
ÖZ
Çalışmanın temel amacı; COVID-19‘un devam eden semptomlarının tedavisine katkıda bulunacak, değişen hasta beklentilerine cevap verebilecek ve pandemi ile yükü artan ve kaynakları azalan sağlık hizmeti sunumunu destekleyecek nitelikte fizyoterapi, sağlıklı yaşam ve danışmanlık merkezlerinin kurulmasına yönelik fizyoterapistlerin girişimcilik niyeti ve buna engel olan unsurlar arasındaki ilişkinin incelenmesidir. Çalışmanın temel amacına uygun olarak kolayda örneklem metodu ile 351 fizyoterapiste ulaşıldı. Katılımcıların sosyodemografik ve mesleğe yönelik bilgileri tarafımızca hazırlanan "Kişisel ve Mesleğe Yönelik Bilgi Toplama Formu" ile sorgulandı. Girişimcilik Niyeti Ölçeği ve Girişimcilik Engelleri Ölçeği kullanılarak analize ilişkin veriler elde edildi. Toplanan veriler SPSS 22.0 ve SmartPLS aracılığıyla analiz edildi.
\end{abstract}

Sonuçlar fizyoterapistlerin girişimcilik niyetinin "kısmen katılıyorum" seviyesinde olduğu ve geliştirilmesi gerektiğini göstermektedir. Ayrıca girişimcilik niyeti üzerinde en büyük etkinin başarısızlık korkusu olduğu ve bunu algılanan destek eksikliğinin takip ettiği tespit edildi $(\mathrm{p}<0,05)$. Algılanan yetkinlik eksikliğinin istatistiki olarak bir etkisinin olmadığı görüldü $(p>0,05)$. Çalışmanın sağlık alanında girişimcilik niyeti kavramına ilişkin literatürü genişletirken, uygulamaya yönelik önerileriyle de önemli katkılar sağlayacağı düşünülmektedir.

Anahtar Kelimeler: Engeller, Fizyoterapi, Girişimcilik niyeti

\begin{abstract}
The main purpose of the study is the investigating the relationship between the entrepreneurial intention of physiotherapists and the factors that prevent this, for the establishment of physiotherapy, wellness and counseling centers that will contribute to the treatment of the ongoing symptoms of COVID-19, respond to changing patient expectations and support healthcare provision whose burden and resources are reduced by the pandemic Following the main purpose of the study, 351 physiotherapists were reached using the convenience sampling method. Socio-demographic and occupational information of the participants were questioned with the "Personal and Professional Information Collection Form" prepared by authors. The data relating to the analysis were obtained by using the Entrepreneurial Intention and the Entrepreneurial Barriers Scales. The obtained data were analyzed through SPSS 22.0 and SmartPLS.

The results show that the entrepreneurial intention of the physiotherapists is at the level of "partially agree" and needs to be improved. Also, it was determined that the greatest impact on entrepreneurial intention is the fear of failure, followed by the perceived lack of support $((\mathrm{p}<0.05)$. It was observed that the perceived lack of competence had no statistical effect $(p>0.05)$. It is thought that while the study expands the literature on the concept of entrepreneurial intention in the field of health, also it will make important contributions with suggestions for practice.
\end{abstract}

Keywords: Barriers, Entrepreneurial intention, Physiotherapy

İstanbul Medipol Üniversitesi Girişimsel Olmayan Klinik Araştırmalar Etik Kurulu Başkanlığı'ndan E-10840098-772.02-2672 evrak sayısı, 21.01.2021 tarihi (Karar no: 53) ile etik izin alınd.

${ }^{1}$ Arş. Gör., İbrahim YIKILMAZ, Yönetim ve Organizasyon, Kocaeli Üniversitesi İktisadi ve İdari Bilimleri Fakültesi İşletme Bölümü, ibrahimyklmz@gmail.com, ORCID: 0000-0002-1051-0886

${ }^{2}$ Dr. Öğr. Üyesi, Seval KUTLUTÜRK, Fizyoterapi ve Rehabilitasyon, İstanbul Medipol Üniversitesi Sağlık Bilimleri Fakültesi Fizyoterapi ve Rehabilitasyon Bölümü, skutluturk@medipol.edu.tr, ORCID: 0000-0001-9120-7071 


\section{GİRIȘ}

Hayatın her alanında etkisini hissettiğimiz COVID-19 pandemisi, Çin (Wuhan)'da görüldüğü 2019 yılından beri tüm dünyaya yayılarak hayatın her alanında etkisini hissettiren bir sorun haline gelmiştir. ${ }^{1} \mathrm{Bu}$ sorun başta sağlık sorunlarına neden olurken, akabinde sosyal ve ekonomik sorunları da tetiklemektedir. Sağlık sorunlarına odaklanan birçok ülke tüm kaynaklarını başta pandemi ile mücadeleye ayırmaktadır. Ancak tedavi süreçleri tamamlanmasına karşın, hastaların çoğunda bazı semptomların kalıcı olarak devam ettiği deneyimlenmektedir. COVID19 'u esas alan ve taburcu olan hastalarda görülen semptomları inceleyen çalışmalarda, özellikle hastalık sonrası 6 ay ve sonrasındaki süreçte tedirginlik verici sonuçlar sunulmaktadır. Taburcu olduktan sonraki 6. aydan itibaren, halen çoğu hastanın abdominal ağrı, koku ve tat almada güçlük, kas güçsüzlüğü, miyalji, fiziksel ve duygusal semptomlar, stres, uyku bozukluğu, mobilite sorunları sergilemeye devam ettiği bildirilmektedir. ${ }^{2-5} \quad \mathrm{Bu} \quad$ belirtilerin çoğunluğunun fizyoterapistlerin ilgi ve uygulama alanına girdiği görülmektedir.

Dünya genelinde yaklaşı 127,455,505 kişinin COVID-19 hastalığına yakalandığ 1 ancak sağlık açısından tek zarar gören kesimin hastalığın görüldüğü kişiler olmayıp, bu sayıdan daha büyük bir kesimin sosyal izolasyon sürecinde yaşam şeklinde meydana gelen değişikliklerden etkilenerek, ciddi sağlık sorunları ile yüzleștiği görülmektedir. ${ }^{6}$ Özellikle pandemi döneminde sosyal izolasyonda evde kalan bireyler üzerinde yapılan çalışmalar; bireylerde fiziksel aktivite düzeylerinin azaldığı, kas iskelet sistemi ağrılarında ciddi bir artışın gözlemlendiği ve yaşam kalitesinin azaldığ 1 yönünde tespitler sunmaktadır. ${ }^{7-10} \mathrm{Bu}$ durumun bireyler üzerinde başta kardiyovasküler hastalıklar, obezite ve diyabet olmak üzere birçok sağlık problemini tetiklediği ifade edilmektedir. ${ }^{11}$ Pandeminin toplum üzerinde yarattığ değerlendirildiğinde; bu sürecin sadece hastanede mevcut salgının tedavisi ile çözülemeyeceği, bu sürecin etkin yönetilmesi için farklı disiplinlerle desteklenecek çok yönlü ve kapsayıcı bir rehabilitasyon sürecinin tesisine yönelik çağrılar yapılmaktadır. ${ }^{12}$ Yukarıda belirtilen, halk sağlı̆̆ını tehdit eden unsurların tedavisinde ve sürdürülebilir çözümünde fizyoterapistlere büyük görev düşmektedir. ${ }^{13}$ Tüm kaynaklarını büyük oranda pandemi ile mücadeleye ayırmış, sağlık sistemini destekleyecek şekilde organize olmuş, çeşitlenen semptomlara cevap verebilecek ve kişiselleştirilmiş rehabilitasyon çözüm önerileri sunan fizyoterapi sağlıklı yaşam ve danışmanlık merkezlerinin varlığının önemli olduğu değerlendirilmektedir. ${ }^{14} \mathrm{Bu}$ kapsamda fizyoterapistlerin kendi danışmanlık merkezlerini kurmaları yani girişimcilik niyetleri ve bunu etkileyen unsurların ayrıntılı bir şekilde ele alınması bu süreç açısından önemlidir.

Girişimcilik niyeti, bireyin bir işi başlatabilmesi için planlı ve bilinçli bir şekilde iși gerçekleștirme niyetini ifade etmektedir. ${ }^{15}$ Çalışma kapsamında özellikle fizyoterapistlerin çeşitlendirilmiş ve kişiselleştirilmiş tamamlayıcı sağlık hizmeti ve danışmanlığı sunmaları yoluyla sağlık sistemini destekleyecek şekilde faaliyet gösterecekleri bir sağlıklı yaşam ve danışmanlık merkezi kurmalarına yönelik niyeti ifade etmektedir. Her ne kadar bir davranışın şekillenmesinde niyet önemli bir belirleyici olsa da; niyetin oluşumuna engel olacak hususlar da etkili olup, önemli bir öncül olarak literatürde incelenmektedir. ${ }^{16,17}$ Fizyoterapistlerin kendi işletmelerini kurmada niyetlerini etkileyen bu önemli öncül (engeller) çalışma kapsamında ayrıntılı bir şekilde ele alınmıştır. Farklı çalışmalarda farklı başlıklar üzerinden girişimcilik engelleri incelense de özellikle 3 temel engelin belirgin olduğu görülmektedir. ${ }^{18,19}$ $\mathrm{Bu}$ üç temel engel; başarısızlık korkusu, algılanan destek eksikliği ve yetkinlik eksikliği şeklindedir. ${ }^{20-23}$

Çalışmanın temel amacı sürdürülebilir halk sağlığı ve sağlık sistemini destekleyecek şekilde pandemi sonrası süreçte fizyoterapistlerinin kendi sağlıklı yaşam ve 
danışmanlık merkezlerini kurma niyetleri ve deneyimledikleri engeller arasındaki ilişkinin incelenmesidir. Çalışmanın COVID-19 pandemisi döneminde sağlık sektöründe çok az çalışmanın incelediği girişimcilik niyeti ve engellerini ele alması ile literatüre ve karar mekanizmalarının uygun politikalar geliştirmesinde uygulamaya önemli katkılarının olacağı değerlendirilmektedir. ${ }^{24}$

\section{MATERYAL VE METOT}

\section{Araștırmanın Etik Yönü}

Çalışma için etik kurul onayı İstanbul Medipol Üniversitesi Girişimsel Olmayan Klinik Araştırmalar Etik Kurulu Başkanlığı'ndan E-10840098-772.02-2672 (Karar no: 53) evrak sayısı ile alındı. Çalışmaya katılmayı kabul eden fizyoterapistler çalışma hakkında bilgilendirilerek onamları alındı ve Helsinki Deklerasyonu'na uygun olarak yürütüldü.

\section{Süreç}

Çalışma, Türkiye'deki halk sağlığı kisitlamaları sirasında Ocak 2021 - Şubat 2021 tarihleri arasında gerçekleștirildi. Çalışmaya dahil edilme kriterleri olarak; fizyoterapi ve rehabilitasyon bölümü lisans mezunu olmak, anket sorularını eksiksiz olarak cevaplamak ve çalışmaya katılmayı kabul etmek olarak belirlendi. Dışlama kriterleri ise; fizyoterapi dişında diğer disiplinlerden lisans derecesine sahip olmak ve çalışmaya katılmayı kabul etmemektir. Çalışmaya dahil edilen fizyoterapistlerin demografik bilgileri, girişimcilik niyetleri ve girişimcilik niyetini engelleyen faktörler çevrimiçi anket (Google anketler) aracılığıyla sorguland1.

\section{Veri Toplama Araçları}

Kişisel ve Mesleğe Yönelik Bilgi Toplama Formu: $\mathrm{Bu}$ form ile katılımciların yaş, cinsiyet, eğitim düzeyi, ailedeki girişimci olma durumu, mesleklerine yönelik yetkinlik algıları ve çalışma durumu kaydedildi.

\section{Girișimcilik Niyeti Ölçeği (GNÖ):} Fizyoterapistlerin girișimcilik niyetleri; Liñan ve Chen (2009) tarafindan geliştirilen, Şeşen ve Basım (2012) tarafından Türkçe'ye uyarlanan ve 6 (altı) ifadeden oluşan GNÖ ile incelenmiştir. ${ }^{25}$ Ölçek 7'li likert tipinde 6 maddeden oluşmaktadır $\quad(1=$ Kesinlikle katılmiyorum, $\quad 7=$ Kesinlikle katıliyorum). Ölçek bireylerin girişimci olmaya dair niyetlerini ölçmeyi amaçlamaktadır. Ölçekten alınan yüksek puan, katılımcıların girişimcilik niyetinin yüksek olduğunu göstermektedir.

Girişimcilik Engelleri Ölçeği (GEÖ) : Fizyoterapistlerin girișimcilik niyeti üzerinde etkili olabilecek engeller; Shinnar et al. (2012) tarafından geliștirilen ve Dölarslan, Koçak ve Walsh (2020) tarafindan Türkçe'ye uyarlanan GEÖ aracılığıyla incelenmiştir. ${ }^{18}$ Algılanan destek eksikliği, başarısızlık korkusu ve algılanan yetkinlik eksikliği olmak üzere 3 alt boyuttan ve 7'li likert tipinde 9 ayrı ifadeden oluşmaktadır (1=Kesinlikle katılmıyorum, 7=Kesinlikle kat1lıyorum). Her engelden alınan puanın yüksekliği o engelin katılımcılar için önemli olduğunu ifade eder.

\section{İstatiksel Analiz}

Çalışmanın amacına uygun olarak toplanan verilerin istatiksel analizi SPSS 22.0 paket programı ve SmartPLS V3.0 programı kullanılarak yapıldı. Tanımlayıcı istatistik bulguları sayı (n), frekans (\%), minimum, maksimum, ortalama $(\overline{\mathrm{x}})$ ve standart sapma (SS) değerleri verilerek paylaşıldı. Değişkenler arasındaki etkinin ve modelin analizi için gereken uyum iyiliği ve hipotez testleri için "Yapısal Eşitlik Modellemesi" Smart PLS programı aracılığıyla test edildi. $\mathrm{Bu}$ programin kullanılmasinın nedeni; değişkenler arası ilișkinin tespitinde daha güçlü istatistiki yapıya sahip olması, normal dağılım gerektirmemesi yönüyle uygulayıcılara büyük kolaylıklar sunması ve ikinci kuşak YEM model olmasıdır. ${ }^{26,27}$ İstatistiksel anlamlılık düzeyi 0,05 olarak belirlendi. 


\section{Araștırmanın Kısıtlılıkları}

Çalıșmanın kısıtlılıkları bulunmaktadır. Öncelikle çalışma kesitsel bir çalışmadır. Gelecek çalışmaların boylamsal nitelikte olması, daha genellenebilir sonuçlar ortaya koyabilir. Ayrıca çalışmada literatürde üzerinde durulan ve girişimcilik niyetini engelleyen 3 değişken üzerinde durulmuştur. Daha kapsamlı ve geniş bir etki analizi için farklı engellerin modele eklenerek gelecek çalışmalarda yer almasının daha uygun olacağı değerlendirilmektedir.

\section{BULGULAR VE TARTIŞMA}

Çalışmaya katılan fizyoterapistlerin demografik özellikleri incelendiğinde; yaş ortalamas1 25,23 $\pm 3,17, \% 75$ 'nin kadın, \%53'nün halihazırda bir işinin olduğu görülmektedir. Mesleki tecrübeleri, ortalama 7,07 (min:1, maks:24) çalışma yılıdır. Eğitim seviyelerinin çoğunlukla lisans düzeyinde olduğu $(\% 56,7)$, işlerine yönelik yetenek algilarında kendilerini yeterli hissettikleri $(\% 70,4)$ ve ailelerinde çoğunlukla girişimci bireylerin $(\% 54,7)$ yer aldığ 1 görülmektedir.

Çalışmanın verileri Kısmi En Küçük Kareler yaklaşımı kullanılarak Yapısal Eşitlik Modelleme (SEM) modelinin yardımı ile analiz edilmiştir. Analizde iki aşamalı analitik süreç izlenmiştir. $\mathrm{Bu}$ aşamalardan ilki ölçüm modelinin geçerlik ve güvenirliğinin tespitidir. İkinci aşama ise; geçerli ve güvenilir olduğu tespit edilen ölçüm modelinin yapısal model olarak ele alınması ve hipotezlerin sinanmasıdır. Bu aşamalar ayrıntılı bir șekilde aşağıda açıklanmıştır.

\section{1. Ölçüm Modeli}

Analizin ilk aşaması olan ölçüm modelinde, araştırma modelinin geçerlik ve güvenirliği incelenir. Tablo 1'de çalışmanın ölçüm modeline ilişkin sonuçlar ayrıntılı bir şekilde paylaşılmıştır. Tablo 1'de tüm yapıların faktör yüklerinin eşik değer olan " 0,70 " nin üzerinde olduğu görülmektedir. ${ }^{28}$ Hem Cronbach alpha hem de Birleșik güvenirlik (CR: Composite Reliability) referans değer olan " 0,70 ” den yüksektir. Bu sonuçlar araştırma modelinin güvenilir olduğunu göstermektedir. Buna ek olarak ortalama varyansin (AVE: Average Variance Extracted) eşik değer olan " 0,50 ” den büyük olduğu görülmektedir. Bu durum araştırma modelinin yakınsak geçerliliğine sahip olduğunu göstermektedir. ${ }^{29}$ Çalışmanın varyans şişme değerlerinin (VIF: Variance Inflation Factor) eşik değer olan "10" dan küçük olduğu görülmüş ve çoklu doğrusallığın (multicollinearity) olmadığ1 tespit edilmiştir. ${ }^{30}$

Tablo 1. Ölçüm Modeline İlişkin Analiz Sonuçları

\begin{tabular}{|c|c|c|c|c|c|c|}
\hline Yapı & İfade & $\begin{array}{c}\text { Faktör } \\
\text { Yükleri }\end{array}$ & Ort \pm SS & $\begin{array}{c}\text { C. } \\
\text { Alpha }\end{array}$ & CR & AVE \\
\hline \multirow{6}{*}{$\begin{array}{l}\text { Girişimcilik } \\
\text { Niyeti } \\
(\text { GN) }\end{array}$} & GN1 & 0,89 & \multirow{6}{*}{$4,92 \pm 1,82$} & \multirow{6}{*}{0,97} & \multirow{6}{*}{0,97} & \multirow{6}{*}{0,86} \\
\hline & GN2 & 0,93 & & & & \\
\hline & GN3 & 0,95 & & & & \\
\hline & GN4 & 0,95 & & & & \\
\hline & GN5 & 0,90 & & & & \\
\hline & GN6 & 0,94 & & & & \\
\hline \multirow{4}{*}{$\begin{array}{l}\text { Algılanan } \\
\text { Destek } \\
\text { Eksikliği } \\
\text { (ADE) }\end{array}$} & ADE1 & 0,71 & \multirow{4}{*}{$1,68 \pm 0,66$} & \multirow{4}{*}{0,78} & \multirow{4}{*}{0,85} & \multirow{4}{*}{0,59} \\
\hline & ADE2 & 0,79 & & & & \\
\hline & ADE3 & 0,76 & & & & \\
\hline & ADE4 & 0,81 & & & & \\
\hline \multirow{4}{*}{$\begin{array}{l}\text { Algılanan } \\
\text { Yetkinlik } \\
\text { Eksikliği } \\
\text { (AYE) }\end{array}$} & AYE1 & 0,73 & \multirow{4}{*}{$1,58 \pm 0,60$} & \multirow{4}{*}{0,78} & \multirow{4}{*}{0,84} & \multirow{4}{*}{0,57} \\
\hline & AYE2 & 0,77 & & & & \\
\hline & AYE3 & 0,84 & & & & \\
\hline & AYE4 & 0,67 & & & & \\
\hline $\begin{array}{l}\text { Başarısızlık } \\
\text { Korkusu } \\
\text { (BK) }\end{array}$ & BK & 1,00 & $3,17 \pm 1,23$ & 1,00 & 1,00 & 1,00 \\
\hline
\end{tabular}

Araștırma modelinin ayrıșma geçerliliği Fornell ve Larcker kriterine göre incelenmiştir. $\mathrm{Bu}$ kriter kapsamında modelin ayrışma geçerliliğine sahip olabilmesi için her bir değişkenin AVE'sinin karekökü, o sütundaki diğer değerlerden büyük olmalıdır. Tablo 2 incelendiğinde koyu renkli olarak verilen değerlerin, diğer değişkenler arası korelasyonlardan büyük olduğu görülmektedir. $\mathrm{Bu}$ durum çalışmamızın ayrışma geçerliliğine sahip olduğunu göstermektedir. ${ }^{31}$ 
Tablo 2. Fornell ve Larcker Kriteri Değerleri

\begin{tabular}{llccc}
\hline & GN & BK & ADE & AYE \\
\hline GN & $0,932 *$ & & & \\
BK & $-0,259$ & $1,000^{*}$ & & \\
ADE & $-0,189$ & $-0,214$ & $0,772 *$ & \\
AYE & $-0,120$ & $-0,153$ & 0,382 & $0,760^{*}$ \\
\hline * AVE'nin karekökünü ifade etmektedir. & &
\end{tabular}

* AVE'nin karekökünü ifade etmektedir.

\section{Yapisal Model}

Analiz sürecine araştırma modelinin gerekli güvenirlik ve geçerlilik şartlarını sağlamasını müteakip, yol analizinin yani yapısal modelin incelenmesi ile devam edilmektedir. $\mathrm{Bu}$ analiz süreci kapsamında, dışsal ve içsel değişkenler arası ilişki ve etkileri göstermek adına $\mathrm{R}^{2}$, yol katsayıları " $\beta$ ", tahmine yönelik " $\mathrm{Q}$ ", $\mathrm{t}$ değerleri ve hipotez testlerinin sonuçları bootsrapping (ön yükleme) metodu (1000 örneklem) ile test edilir ve sonuçlar paylaşılır. ${ }^{30} \mathrm{Bu}$ veriler Tablo 3'de sunulmuştur.

Tablo 3. Yapısal Modelin Analizine İlişskin Değerler

\begin{tabular}{lllllllllr}
\hline Değişkenler & $\boldsymbol{\beta}$ & \multicolumn{1}{l}{ SH } & \multicolumn{1}{l}{$\mathbf{t}$} & $\mathbf{p}$ & $\mathbf{R}^{\mathbf{2}}$ & $\mathbf{Q}^{\mathbf{2}}$ & $\mathbf{f}^{2}$ & $\begin{array}{r}\text { Hipotez } \\
\text { No }\end{array}$ & \multicolumn{1}{c}{ Durum } \\
\hline BK -> GN & $-0,32$ & 0,05 & 6,19 & 0,001 & & & 0,11 & H1 & Kabul \\
ADE -> GN & $-0,22$ & 0,05 & 3,90 & 0,001 & 0,13 & 0,11 & 0,04 & H2 & Kabul \\
AYE -> GN & $-0,08$ & 0,07 & 1,16 & 0,24 & & & 0,007 & H3 & Red \\
\hline
\end{tabular}

BK: Başarısızlık Korkusu, GN: Girişimcilik Niyeti, ADE: Algılanan Destek Eksikliği, AYE: Algılanan Yetkinlik Eksikliği, H: Hipotez, $\mathrm{f}^{2}$ : Etki boyutu, $R^{2}$ : Etki durumu, $Q^{2}$ : Tahmin gücü, $\beta$ : Yol katsayısı, SH: Standart Hata, İstatistiksel anlamlılık: $p<0,05$.

Yapılan analizde, öncelikle modelin uyum iyiliği SRMR (standardize edilmiş kök ortalama kare artı) ile incelenerek 0,065 değerinin eşik değerden yüksek olması sebebiyle uygun bulunmuştur. ${ }^{32}$ Girişimcilik niyeti üzerinde içsel değişkenlerin (BK, ADE ve AYE) düşük seviyede bir etkisinin olduğu görülmektedir. ${ }^{33}$ İki bağımsız değişkenin (BK ve ADE) birlikte toplam \%13,5'lik bir etkiyi açıkladığı belirlenmiştir. Ancak AYE değișkeninin girișimcilik niyeti üzerinde istatistiki olarak anlamlı bir etkisinin olmadığ ${ }_{1}$ tespit edilmiştir $(\beta=-0,082, t=1,166$, $\mathrm{p}>0,05)$. Girişimcilik niyeti üzerinde en büyük etkinin BK değişkenine (\%32) ait olduğu görülmektedir. Diğer değişken olan ADE ise \%22,6 oranında bir etkiye sahiptir. " $\mathrm{f}$ " " değeri herhangi bir değişkenin modelden çıkarılması halinde $\mathrm{R}^{2}$ de meydana gelen değişikliği ifade eder. $\mathrm{Bu}$ modelde yine $\mathrm{BK}$ değișkeninin, ADE değișkenine göre $(0,112)$ daha büyük etkisinin olduğu görülse de her iki değişkenin (BK:0,112, ADE:0,049) düşük seviyede etki gücünün olduğu görülmektedir. ${ }^{33} \mathrm{Q}^{2}$ değerinin sıfırdan büyük olmas1 yapısal modelin tahmin gücüne sahip olduğunu ifade etmektedir. ${ }^{34}$
Dünyayı etkisi altına alan ve yașamın her alanında kalıcı etkiler bırakan COVID-19 pandemisi, halihazırda sağlık sisteminin yükünü daha da arttırmıştır. Artan bu yüke önemli ölçüde kaynak ayırmak zorunda kalan sağlık sistemi, çeşitlenen sağlik hizmetleri ve beklentilere cevap verebilmek adına çeșitli yöntemler üstlense de yapılan çalıșmalarda pandeminin etkisinin uzun vadeli olarak devam edeceği ve mücadelede farklı disiplin ve aktörlerin katılımının sürdürülebilir halk sağlığı açısından önemli olduğu vurgulanmaktadır. $\quad \mathrm{Bu}$ kapsamda fizyoterapistlerin, COVID-19 pandemisi ile ortaya çıkan koku ve tat almada güçlük, kas güçsüzlügü, stres, uyku bozukluğu, mobilite sorunları, kardiyovasküler hastalıklar, kas iskelet sistemi ağrıları ve solunum sorunları gibi fiziksel ve duygusal semptomlar ile çeşitlenen sağlık problemlerinin çözümün de sağllk sistemini destekler nitelikte kendi sağlıklı yaşam ve danışmanlık merkezlerini kurma niyetleri ve buna engel teşkil edecek unsurlar incelenmiştir. Çalışmanın sonuçları göstermektedir ki; fizyoterapistlerin girişimcilik niyetlerinin "kısmen katılıyorum" seviyesinde olduğu, girişimcilik niyetleri 
üzerinde en önemli unsurun başarısızlık korkusu ve akabinde algilanan destek eksikliğinin yer aldığı ve yetkinliğin bu süreçte etkisinin olmadığı tespit edilmiştir. Çalışmanın sonuçlarına ilişkin detaylar aşağıda sunulmuştur. Girişimcilik niyeti, fizyoterapistlerin kendi danışmanlık merkezlerini açmaya yönelik planlı ve bilinçli bir şekilde niyetlerini hayata geçirmeyi ifade etmektedir. Girişimci bireylerin sayısının artması hem ekonomi hem de çeşitlenen ve özelleştirilmiş sağlik hizmetlerinin sunulması açısından önemlidir. Hem pandemi döneminde artan işsizlik için alternatif bir çözüm sunarken, hem de sağlık sistemi üzerinde oluşan yükün azaltılması açısından önemlidir. Bu kapsamda çalışmaya katılan fizyoterapistlerin \%63,2'sinin işinin olduğu ancak \%36,8'nin halen işsiz olduğu görülmektedir. İşi olanların çoğu, bir kurum çatısı altında çalışmakta ve kendi işine sahip olmadığını ifade etmektedir. Girişimcilik niyetleri ise; "kısmen kat1lyyorum" seviyesindedir. Yani bir iş kurma noktasında orta seviyede niyetlerinin olduğu ve bu durumun geliştirilmeye ihtiyacı olduğu görülmektedir. Sağlık Bilimleri Fakülteleri özelinde girişimcilik niyeti tespiti yapan çalışmalar incelendiğinde mevcut Fizyoterapi ve Rehabilitasyon Bölümü öğrencilerinin görece diğer bölümlere göre daha yüksek girişimcilik niyetine sahip olduğ ${ }^{35}$ ve çalışmanın sonucunu destekler nitelikte genel girişimcilik eğiliminin orta seviyede olduğu görülmektedir. ${ }^{36}$ Gerek sağlık hizmetlerinin sunumunda sistemin desteklenmesi, gerekse uzman bireylerin kendi işlerini kurmalarında, karar vericilerin bireylerin girişimcilik niyetlerini geliştirecek ve destekleyecek şekilde tedbirler alması önemlidir. Nitekim sağlık alanında girişimciliğin arttırılması ile sağlık hizmetlerinde kalite ve yeniliğin artacağ1 ve sağlık sektöründe meydana gelen sorunların çözümünde önemli bir etkisi olacağı vurgulanmaktadır. ${ }^{37} \mathrm{Bu}$ kapsamda özendirici proje yarışmalarının düzenlenmesi, teşvik ve destek bütçelerinin yeni mezunlara düşen payının arttırılması ve sadece İktisadi ve İdari Bilimler Fakülteleri müfredatında değil, tüm disiplinlerin müfredatında girişimcilik derslerinin yer almasinın bu sürece olumlu katkılarda bulunacağ değerlendirilmektedir.

Fizyoterapistlerin uzmanlık içeren yeteneklerine karşın, görece girişimcilik niyetlerinin yüksek çıkmamasının ardında birtakım sebeplerin yer aldığı düşünülmüştür. $\mathrm{Bu}$ kapsamda; algılanan destek eksikliği, başarısızlık korkusu ve algılanan yetkinlik eksikliği kriterleri açısından girişimcilik niyetlerinin nasıl etkilendiği incelenmiştir. Çalışmanın sonuçları fizyoterapistlerin girişimcilik niyetlerini etkileyen en önemli unsurun başarısızlık korkusu olduğunu göstermektedir. $\mathrm{Bu}$ etkiyi algılanan destek eksikliği izlemektedir. Algılanan destek eksikliğinin aile veya kurumların finansal destek ve çeşitli konularda girişimci adaya sağladığı desteğe ilişkin yoksunluk olarak tanımlamaktadır. Ayrıca Küresel Girişimcilik İzleme Örgütü'ne göre; girişimcilik niyetinin önündeki en büyük engelin başarısızlık korkusu olduğu ifade edilmektedir. ${ }^{18}$ Yine meslek yüksek okullarında eğitim gören öğrencileri inceleyen bir çalışmada da benzer şekilde girişimcilik niyetinin önündeki en belirgin psikolojik etmenin başarısızlık korkusu olduğu tespit edilmiştir. ${ }^{38}$ Türk Üniversitelerinde girişimcilik niyetini belirleyen unsurları inceleyen bir diğer çalışmada da; aile, yapısal ve finansal desteğin belirleyici bir unsur olduğu görülmüștür. ${ }^{39}$ Çalışmanın sonucunun daha önceki çalışmaları destekler nitelikte olduğu görülmektedir. Algılanan destek eksikliği; aile ve kurumların kendi işlerini kurmada fizyoterapistlere gerekli desteği vermemesinin, girişimcilik niyetlerini azalttığını göstermiştir. Buna ek olarak başarısızlık korkularının da yüksek olduğu görülmüştür. $\mathrm{Bu}$ sonuçlar öncelikle kurum olarak devlet ve politika uygulayıcılarının ilk olarak destek ve bilgilendirme faaliyetlerini geliştirmelerinin önemli olduğunu ortaya koymuştur. Kurumların ailelere yönelik de bilgilendirme ve özendirme politikaları sayesinde, girişimci eylem içerisine girmek isteyen bireyin destek noktasinda kendine güveninin oluşabileceği, başarısızlık korkusunun da bu sayede azaltılabileceği değerlendirilmektedir. Çalışmanın sonuçları arasında algılanan yetkinlik eksikliğinin 
girişimcilik niyeti üzerinde istatistiki olarak anlamlı bir etkisinin olmadığı tespit edilmiştir. Yetkinlik eksikliği; iş ile alakalı gerekli eğitim ve donanıma sahip olmamaktır. Önceki çalışmalarda girişimcilik niyeti üzerinde etkili bir engel olduğu tespit edilmiştir. ${ }^{18} \quad$ Ancak çalışmamızda fizyoterapistlerin uygulamalı eğitim görmesi ve mezuniyetlerinin payında teorikten ziyade pratik eğitimin baskın olması, onların uzmanlıklarını uygulamada gerekli olan bilgi ve yetenek setine sahip olmaların sağlamıştır. Demografik sorularda yer alan işlerine yönelik gerekli yetkinliğe sahip olup olmadıkları sorulduğunda, \%70,4 gibi oldukça yüksek bir seviyede kendilerini yeterli donanıma sahip olarak gördükleri tespit edilmiştir. Çalışmanın bu sonucunun diğer çalışmalardan farklı olmasının kendilerini oldukça yetkin görmelerinden kaynaklandığı değerlendirilmektedir.

\section{SONUÇ VE ÖNERILER}

İçinde bulunduğumuz COVID-19 pandemisinin hem sağlık hem de sosyoekonomik alanlarda yarattığı etkinin azaltılması, farklılaşan ve çeşitlenen hasta beklentilerinin karşılanması, sürdürülebilir sağlık hizmetinin sunumu adına sağlık sistemini destekleyecek ve COVID-19 semptomlarının çoğunun kalıcı çözümünde aktif katkısı bulunabilecek fizyoterapistlerin kendi sağlıklı yaşam ve danışmanlık merkezlerini kurma niyetleri ve olası engel koşullarının incelenmesi önemli bir yere sahiptir. $\mathrm{Bu}$ önemi esas alarak, yürütülen çalışmanın sonuçlarının COVID-19 ve girişimcilik kavramları arasındaki ilişkiye, sağlık alanındaki girișimciliği esas alan sınırlı sayıdaki literatüre önemli katkıları olduğu değerlendirilmektedir. Ayrıca karar mekanizmalarına ve politika geliştiricilere yönelik önerileri ile uygulamaya da önemli katkılar sunacağı düşünülmektedir.

KAYNAKLAR

1. World Health Organization. (2020). "Middle Eas Respiratory Syndrome Coronavirus (MERS-CoV)", Erişim adresi: https://www.who.int/news-room/factsheets/detail/middle-east-respiratory-syndromecoronavirus-(mers-cov) (Erişim tarihi: 05.03.2021)

2. Huang, C, Huang, L, Wang, Y, Li, X, Ren, L, Gu, X. and Cao, B. (2021). "6-Month Consequences of COVID-19 in Patients Discharged From Hospital: A Cohort Study". The Lancet, 397 (10270), 220-232.

3. Garrigues, E, Janvier, P, Kherabi, Y, Le Bot, A, Hamon, A, Gouze, H. and Nguyen, Y. (2020). "Post-discharge Persistent Symptoms and Health-Related Quality of Life After Hospitalization for COVID-19". Journal of Infection, 81 (6), e4-e6.

4. Carfi, A, Bernabei, R. and Landi, F. (2020). "Persisten Symptoms in Patients After Acute COVID-19". Jama, 324 (6), 603-605.

5. Halpin, S.J, McIvor, C, Whyatt, G, Adams, A, Harvey, O, McLean, L. and Sivan, M. (2021). "Postdischarge Symptoms and Rehabilitation Needs in Survivors of COVID-19 Infection: A Crosssectional Evaluation". Journal of Medical Virology, 93 (2), 1013-1022.

6. Worldmeters. (2021). Erişim adresi https://www.worldometers.info/coronavirus/?utm_campa ign=homeAdvegas1? (Erişim tarihi: 20.03.2021)

7. Faraji, S, Ghayour Najafabadi, M, Rostad, M. and Anastasio, A.T. (2020). "The Effect of COVID-19 Quarantine on Physical and Social Parameters of Physical Education Providers and Youth Sport Coaches". Work, (Preprint), 1-3.
8. Shariat, A, Ghannadi, S, Anastasio, A, Rostad, M. and Cleland, J.A. (2020). "Novel Stretching and Strength Building Exercise Recommendations for ComputerBased Workers During the COVID-19 Quarantine". Work, (Preprint), 1-11.

9. Memari, A, Shariat, A, Anastasio, A. and Hakakzadeh, A. (2020). "Rising Incidence of Musculoskeletal Discomfort in the Wake of the COVID-19 Crisis". Work, (Preprint), 1-3.

10. Ferreira, L.N., Pereira, L.N., da Fé Brás, M. and Ilchuk, K. (2021). "Quality of Life Under the COVID-19 Quarantine”. Quality of Life Research, 1-17.

11. Mattioli, A.V., Ballerini Puviani, M, Nasi, M. and Farinetti, A. (2020). "COVID-19 Pandemic: the Effects of Quarantine on Cardiovascular Risk". Eur J Clin Nutr, $74,852-855$

12. Ladds, E, Rushforth, A, Wieringa, S, Taylor, S, Rayner, C, Husain, L. and Greenhalgh, T. (2020). "Persistent Symptoms After COVID-19: Qualitative Study of 114 'Long COVID' Patients and Draft Quality Principles for Services". BMC Health Services Research, 20 (1), 1-13.

13. Demeco, A, Marotta, N, Barletta, M, Pino, I, Marinaro, C, Petraroli, A. and Ammendolia, A. (2020) "Rehabilitation of Patients Post-COVID-19 Infection: a Literature Review". Journal of International Medical Research, 48 (8), 1-10.

14. Korona Virüs Salgını. (2020). Erişim adresi: https://t24.com.tr/haber/koronavirus-salgini-COVID-19disindaki-hastaliklarin-tedavisi-aksiyor,872666 (Erişim tarihi:12.02.2021). 
15. Thompson, E.R. (2009). "Individual Entrepreneurial Intent: Construct Clarification and Development of an Internationally Reliable Metric". Entrepreneurship Theory and Practice, 33 (3), 669-694.

16. Trivedi, R.H. (2017). "Entrepreneurial-Intention Constraint Model: A Comparative Analysis among PostGraduate Management Students in India, Singapore and Malaysia". International Entrepreneurship and Management Journal, 13 (4), 1239-1261.

17. Sharma, L. (2018). "Entrepreneurial Intentions and Perceived Barriers to Entrepreneurship among Youth in Uttarakhand State of India". International Journal of Gender and Entrepreneurship, 14 (4), 243-69.

18. Dölarslan, E.Ş., Koçak, A. and Walsh, P. (2020). "Perceived Barriers to Entrepreneurial Intention: The Mediating Role of Self-Efficacy". Journal of Developmental Entrepreneurship, 25 (03), 2050016.

19. Liñán, F. and Chen, Y.W. (2009). "Development and Cross-cultural Application of a Specific Instrument to Measure Entrepreneurial Intentions". Entrepreneurship Theory and Practice, 33, 593-617.

20. Cacciotti, G. and Hayton, J.C. (2015). "Fear and Entrepreneurship: A Review and Research Agenda". International Journal of Management Reviews, 17, 16590.

21. Monitor G.E. (2018). "Global Report 2017/18”. Global Entrepreneurship Research Association (GERA).

22. Schlaegel, C, Engle, R.L, Dimitriadi, N. and Taureck, P.C. (2015). "Why not now?. Triggers and Barriers of New Venture Creation: a Meta-Analysis and Multinational Comparison of Entrepreneurs Perspectives". International Journal of Entrepreneurial Venturing, 7, 227-50.

23. Mitchelmore, S. and Rowley, J. (2010). "Entrepreneurial Competencies: a Literature Review and Developmen Agenda". International Journal of Entrepreneurial Behavior and Research, 16, 92-111.

24. Marques, C.S., Valente, S. and Lages, M. (2018). "The Influence of Personal and Organisational Factors on Entrepreneurship Intention: an Application in the Health Care Sector". Journal of Nursing Management, 26 (6), 696-706.

25. Şeşen, H. ve Basım, H.N. (2012). "Demografik Faktörler ve Kișiliğin Girisimcilik Niyetine Etkisi: Spor Bilimleri Alanında Öğrenim Gören Üniversite Öğrencileri Üzerine Bir Araştırma”. Ege Akademik Bakıș, 12, 21-28.

26. Shackman, J.D. (2013). "The Use of Partial Least Squares Path Modeling and Generalized Structured Component Analysis in International Business Research: a Literature Review". International Journal of Management, 30 (3), 78-86.

27. Chin, W.W. (2010). "How to Write Up and Report PLS Analyses". In Handbook of Partial Least Squares, Springer, Berlin, Heidelberg, 655-690.

28. Vinzi, V.E, Chin, W.W, Henseler, J. and Wang, H (2010). "Handbook of Partial Least Squares". Berlin: Springer, 201, 0

29. Hair Jr, J.F, Matthews, L.M, Matthews, R.L, an Sarstedt, M. (2017). "PLS-SEM or CB-SEM: Updated Guidelines on Which Method to Use". International Journal of Multivariate Data Analysis, 1 (2), 107-123.
30. Filho, D.F, Silva, L, Rocha, E. and Domingos, A. (2016) "How to Get Away with Multicollinearity: a Users' Guide". Revista Política Hoje, 25 (2), 161-174.

31. Fornell, C. and Larcker, D.F. (1981). "Evaluating structural equation models with unobservable variables and measurement error". Journal of marketing research, $18(1), 39-50$

32. Henseler, J, Ringle, C.M. and Sarstedt, M. (2015). “A New Criterion for Assessing Dis-criminant Validity in Variance-based Structural Equation Modeling". Journal of the Academy of Marketing Science, 43 (1), 115-135.

33. Hair, J.F, Risher, J.J, Sarstedt, M. and Ringle, C.M. (2019). "When to Use and How to Report the Results of PLS-SEM”. European business review, 31 (1), 2-24.

34. Hair Jr, J.F, Hult, G.T.M, Ringle, C. and Sarstedt, M (2016). "A Primer on Partial Least Square Structural Equations Modeling (PLS-SEM)”. Los Angeles: Sage publications.

35. Tanyel Çatak, T. ve Hoşgör, H. (2021). "Üniversite Öğrencilerinin Girişimcilik Eğilimlerinin Belirlenmesi: Sağlık Bilimleri Fakültesi Örneği”. Akademik Sosyal Araştırmalar Dergisi, 9(115),199-218.

36. Ocak, S, Gider, Ö. and Sahin, T. (2019) "Entrepreneurial Tendency of the Students: A Research on the Students of the Department of Physiotherapy and Rehabilitation and Nutrition and Dietetics". Journal of Entrepreneurship and Development, 14(1), 67-77.

37. Itri, J. N., Ballard, D. H., Kantartzis, S., Sullivan, J. C. Weisman, J. A., Durand, D. J., Ali, S. and Kansagra, A P. (2015). "Entrepreneurship in the academic radiology environment". Academic radiology, 22(1), 14-24

38. Akpınar, T. ve Küçükgöksel, N.Ç. (2015). "Meslek yüksekokulu öğrencilerinin girişimcilik algısı ve girişimciliği engelleyen sebepler”. Balkan ve Yakın Doğu Sosyal Bilimler Dergisi, 1(1), 13-19.

39. Yurtkoru, E.S, Kuşcu, Z. K. and Doğanay, A. (2014). "Exploring the antecedents of entrepreneurial intention on Turkish university students". Procedia-Social and Behavioral Sciences, 150, 841-850. 